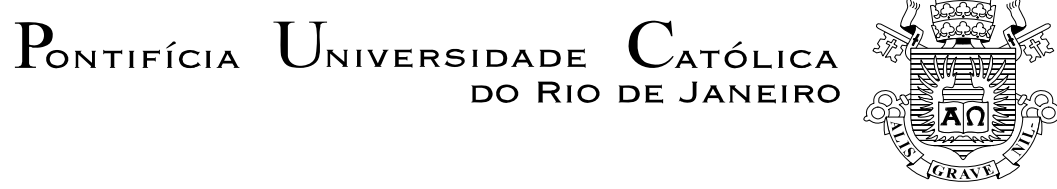

Rodrigo Cazes Costa

CINEMA BRASILEIRO E SUAS POSSIBILIDADES
COMO FORMA DE PENSAMENTO ENSAÍSTICO
Um percurso através de São-Bernardo,
Vidas secas e Insônia

Dissertação de Mestrado

Dissertação de Mestrado apresentada como requisito parcial para obtenção do grau de Mestre em Letras do Departamento de Letras da PUC-Rio como parte dos requisitos parciais para obtenção do título de Mestre em Letras.

Orientadora: Profa. Ana Paula Veiga Kiffer

Rio de Janeiro

Março de 2008 


$$
\text { Pontifícia } U_{\text {niversidade }} \text { Católica }_{\text {Do Rio de Janeiro }}
$$

Rodrigo Cazes Costa

\title{
CINEMA BRASILEIRO E SUAS POSSIBILIDADES COMO FORMA DE PENSAMENTO ENSAÍSTICO Um percurso através de São-Bernardo, Vidas secas e Insônia
}

\begin{abstract}
Dissertação apresentada como requisito parcial para obtenção do grau de Mestre pelo programa de PósGraduação em Letras do Departamento de Letras do Centro de Teologia e Ciências Humanas da PUC-Rio. Aprovada pela Comissão Examinadora abaixo assinada.
\end{abstract}

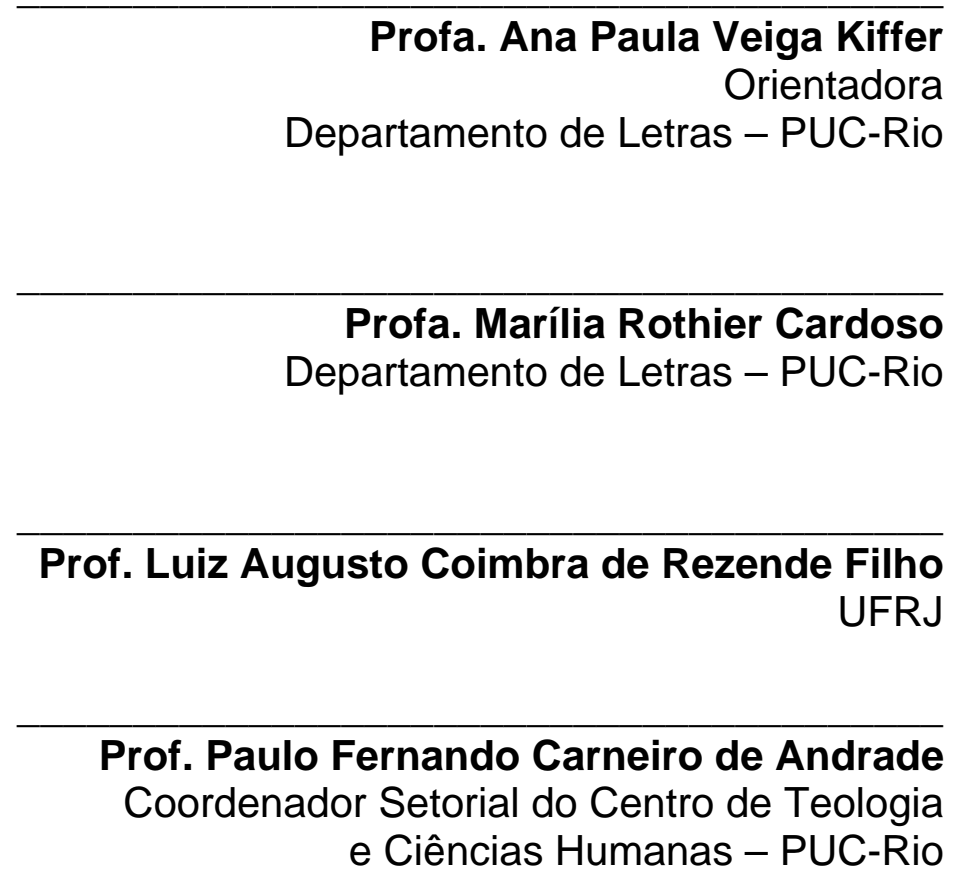

Rio de Janeiro, de de 
Todos os direitos reservados. É proibida a reprodução total ou parcial do trabalho sem autorização do autor, da orientadora e da universidade.

\section{Rodrigo Cazes Costa}

Graduado em Direito pela UFRJ, em 1999 e em Cinema na Estácio de Sá, em 2003. Pesquisador de cinema, em especial o brasileiro

Ficha Catalográfica

Rodrigo, Cazes Costa

CINEMA BRASILEIRO E SUAS POSSIBILIDADES COMO FORMA DE PENSAMENTO ENSAÍSTICO Um percurso através de São-Bernardo, Vidas secas e Insônia / Rodrigo Cazes Costa ; orientadora: Ana Paula Veiga Kiffer. - 2008.

119 f. ; $30 \mathrm{~cm}$

Dissertação (Mestrado em Letras) - Pontifícia Universidade Católica do Rio de Janeiro, Rio de Janeiro, 2008.

Inclui bibliografia

1. Letras - Teses. 2. Cinema brasileiro. 3. Literatura brasileira. 4. Graciliano Ramos. I. Kiffer, Ana Paula Veiga. II. Pontifícia Universidade Católica do Rio de Janeiro. 


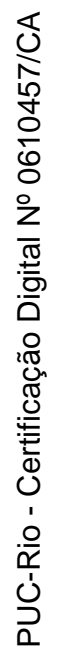

Ao cinema. 


\section{Agradecimentos}

Ao CNPq e a CAPES, pelo apoio financeiro recebido.

À minha mãe, meu pai e meu irmão, sempre presentes.

À minha orientadora, Ana Paula Kiffer, que teve a paciência para me auxiliar nesta tarefa.

Aos professores da PUC, que mostraram novos caminhos em suas aulas, em especial a Marília e o Julinho.

À Chiquinha, pela ajuda nas questões burocráticas.

Aos meus colegas da PUC, em especial: Mariana Patrício, Flávia Leiroz, Flávia Vieira Santos, Carlos Eduardo Motta, Daniel Barretto da Silva, Stella Caymmi, Carolina Magalhães, Mariana Custódio e também a todos os outros que não citei aqui nominalmente, agradeço o incentivo e as cervejas.

A todos os amigos que ajudaram.

Ao Hernani Heffner, pelas suas idéias sobre o cinema brasileiro e pelo apoio. 


\section{Resumo}

Costa, Rodrigo Cazes; Kiffer, Ana Paula Veiga (Orientadora). CINEMA BRASILEIRO E SUAS POSSIBILIDADES COMO FORMA DE PENSAMENTO ENSAÍSTICO Um percurso através de SãoBernardo, Vidas secas e Insônia. Rio de Janeiro, 2008. 119p. Dissertação de Mestrado - Departamento de Letras, Pontifícia Universidade Católica do Rio de Janeiro.

Esta dissertação pretende, através do exame de três filmes transcriados de livros de Graciliano Ramos, São Bernardo, Insônia e Vidas-Secas e por intermédio de uma escrita ensaística, tecer considerações sobre a relação do cinema com a literatura e, principalmente, considerações sobre a construção da historiografia do cinema brasileiro. Analisamos, dentro deste percurso histórico, principalmente os períodos do Cinema Novo e do cinema brasileiro contemporâneo (1995 até os dias de hoje), buscando novas reflexões para esses períodos, que fujam daquelas consagradas pela historiografia dominante sobre o cinema brasileiro.

\section{Palavras-chave}

Cinema brasileiro- literatura brasileira- Graciliano Ramos. 


\section{Abstract}

Costa, Rodrigo Cazes; Kiffer, Ana Paula Veiga (Advisor). BRAZILIAN CINEMA AND ITS POSSIBILITIES AS A WAY OF THOUGHT IN THE MODE OF AN ESSAY A route through São-Bernardo, Vidas secas and Insônia. Rio de Janeiro, 2008. 119p. MSc Dissertation Departamento de Letras, Pontifícia Universidade Católica do Rio de Janeiro.

This thesis intends, through the examination of three movies taken from books of Graciliano Ramos, São Bernardo, Insônia e Vidas Secas, and in a style of writing taken with strong influence from the essay, think about the relations between cinema and literature, and, mainly, about the construction of the the Brazilian cinema’s historiography. We analyze, inside this historical route, mainly the periods of "Cinema Novo" and Brazilian contemporary cinema (1995 until nowadays), searching new reflections for those periods, reflections that escape from that consecrated by the dominant Brazilians cinema historiography.

\section{Keywords}

Brazilian cinema- brazilian literature- Graciliano Ramos. 


\section{Sumário}

1. Introdução

1.1 - Apresentação geral do trabalho 9

1.2 - Conteúdo dos capítulos $\quad 11$

2. O cinema brasileiro como possibilidade de pensamento ensaístico 14

2.1 - Relações possíveis entre cinema e literatura 14

2.2 - O ensaio na literatura e o cinema como possibilidade de ensaio $\quad 19$

2.3 - O Cinema Novo $\quad 24$

$\begin{array}{ll}2.4 \text { - O cinema da retomada } & 27\end{array}$

3. Vidas secas $\quad 34$

3.1 - Vidas secas - nascimento do livro 34

3.2 - Vidas Secas - nascimento do filme 38

3.3 - Vidas secas - a força da palavra 46

3.4 - Vidas secas - documentário da miséria do sertão nordestino 53

4. São Bernardo 64

4.1 - São Bernardo - nascimento do livro 64

4.2 - São Bernardo - nascimento do filme 67

4.3 - São Bernardo - política da escrita $\quad 75$

4.4 - Política em São Bernardo, o filme 82

4.5 - São Bernardo - caminhos para um audiovisual brasileiro 91

5. Insônia 93

5.1 - Insônia - nascimento do livro 93

5.2 - Insônia - nascimento do filme 93

5.3 - Insônia - o conto e o curta metragem 101

5.4 - Dois dedos 102

5.5 - A prisão de J. Carmo Gomes 104

5.6 - Um ladrão 105

5.7 - Insônia - Cinema Novo e preservação do cinema brasileiro 106

5.8 - Insônia - o filme 110

6. Considerações sobre o trabalho e apontamentos para o futuro 113

$\begin{array}{ll}\text { Referências bibliográficas } & 116\end{array}$ 